\title{
PENGGUNAAN KAIDAH FIKIH DALAM FATWA MAJELIS ULAMA INDONESIA TENTANG KEUANGAN SYARIAH
}

\author{
Imron Rosyadi \\ Universitas Mayjen Sungkono | Jl. Irian Jaya No.4, Mergelo, Kranggan, Mojokerto \\ imrosyad69@gmail.com
}

\begin{abstract}
Abstact: This study aims to describe and analyze the use of legal maxims of Islamic law in the fatwas of the Indonesian Ulema Council (MUI) on Islamic finance with content analysis. MUI's fatwas on Islamic finance are amounted to 116 fatwas, using 322 items of rules. The highest number of items according to the cluster of rules which are found on the asasiyah rules are 252 items, then kulliyah rules which well agreed have 47 items, in madhhab's kulliyah there are 17 items, and the last on special rules have 6 items. The highest number of items by category of rules are on the principle of the third asasiy ah rules, I I I items, then the principle of second asasiyah rules have 63 items. From the perspective of content analysis, the use of fikih in the MUl's fatwas on Islamic finance considers the freedom of mu ' amalah to achieve a rapid progress as far as it does not endanger the businessmen and other parties. The signposts are that business should depart from good will, adapt to the traditions of its type of business, and creatively seek solutions to business problems. All matters relating to mu 'amalah involve the role of policy maker to use the principle of benefit in its policy.
\end{abstract}

Key Words: Legal maxim of Islamic law, fatwa, Indonesian Ulema Council, Islamic finance.

Abstrak: Kajian ini bertujuan mendeskripsikan dan menganalisis penggunaan kaidah fikih dalam fatwa Majelis Ulama Indonesia (MUI) tentang keuangan syariah dengan analisis isi. Fatwa MUI tentang keuangan syariah berjumlah I I 6 fatwa, menggunakan 322 item kaidah fikih. Jumlah terbanyak item menurut rumpun kaidah terdapat pada kaidah Asasiyah sebanyak 252 item, selanjutnya kaidah kullîyah yang disepakati 47 item, kaidah kulliyah mazhab 17 item, dan terakhir kaidah khusus 6 item. Jumlah terbanyak item menurut kategori kaidah terdapat pada kaidah asasiyah ketiga sebanyak II I item, selanjutnya

AL-DAULAH: JURNAL HUKUM DAN PERUNDANGAN ISLAM VOLUME 8, NOMOR 2, OKTOBER 2018 p-ISSN 2089-0109; e-ISSN 2503-0922

Homepage: http://jurnalfsh.uinsby.ac.id/index.php/aldaulah Email: judulsj@gmail.com 
kaidah asasîyah ke-2 sebanyak 63 item, dan kaidah-kaidah lainnya. Dari perspektif analisis isi, penggunaan kaidah-kaidah fikih dalam fatwa MUI tentang keuangan syariah mempertimbangkan keleluasaan mu ‘amalah agar mencapai kemajuan pesat sejauh usaha mu'amalah tidak membahayakan pengusaha dan pihak-pihak lainnya. Rambu-rambunya adalah usaha semestinya berangkat dari niat baik, beradaptasi terhadap tradisi jenis usahanya, dan kreatif mencari solusi atas problem-problem usaha. Semua hal yang berkaitan dengan mu 'amalah melibatkan peran policy maker agar menggunakan prinsip kemaslahatan dalam kebijakannya.

Kata Kunci: Kaidah Fikih, Fatwa, Majelis Ulama Indonesia, Keuangan Syariah.

\section{Pendahuluan}

Majelis Ulama Indonesia (MUI) merupakan lembaga keagamaan yang berperan memfasilitasi masyarakat dalam persoalan-persoalan keagamaan umat Islam. Dengan peran ini MUI niscaya menjadi pusat tumpuan, kontrol, dan problem solver permaslahan-permasalahan umat Islam yang berkenaan dengan aspek-aspek akidah, hukum, dan akhlak. Oleh karenanya, sesuai dengan identitasnya MUI memiliki peran strategis dalam dinamika kehidupan keagamaan masyarakat, termasuk di dalamnya masalah-masalah mu'amalah.

Khususnya di bidang hukum, dalam dinamika tersebut terdapat aplikasi hukum Islam dan interaksi MUI sebagai produsen hukum dengan masyarakat luas khususnya di Indonesia. Aplikasi hukum ini berkaitan dengan proses ijtihadiah untuk produksi hukum sesuai dengan permasalahan yang berkembang. Sedang interaksi MUI dengan masyarakat luas merupakan akibat langsung dari produk hukum yang dipublikasikan (difatwakan) di tengahtengah masyarakat sebagai bentuk servis MUI, termasuk label halal bagi makanan dan minuman yang beredar di Indonesiam ${ }^{1}$ di

' Dalam kaitan ini Pradana Boy ZTF menyatakan bahwa fatwa MUI memainkan dua fungsi yang prinsip, yakni: ( I fatwa sebagai instrumen perubahan sosial dan (2) fatsa sebagai instrumen ideologi. Pradana Boy ZTF, "The Functions of Fatwa in Contemporary Muslim Societies: An Indonesian Experience", Salam: Jurnal Studi Masyarakat Islam, Program Pascasarjana Universitas Muhammadiyah Malang Volume I 5 Nomor I Juni 2012, I- 13. 
samping fatwa-fatwa lainnya yang berkenaan dengan kebuangan syariah sebagai contoh. Di sinilah MUI berhadapan dengan kemungkinan apresiasi, evaluasi, feedback, kritik, atau bahkan hujatan dari masyarakat luas. Selain itu, MUI juga berpotensi sebagai lembaga konsultasi hukum dan objek penelitian bagi pengembangan ilmu pengetahuan.

Fatwa MUI sesungguhnya memainkan peran dakwah Islam yang menyangkut tiga unsur dalam sistem Islam, yakni akidah, syariah, dan akhlak. Peran dakwah MUI ini dalam sebagian kasus menekankan fungsi servis dan kontrol hukum Islam. Meskipun dalam sebagian kasus lainnya menekankan pada fungsi dan kontrol akidah dan akhlak masyarakat. Pada konteks inilah MUI pada perjalanan sejarahnya menghasilkan fatwa-fatwa. ${ }^{2}$ Fatwa-fatwa ini pada realitasnya tidak sepenuhnya netral, tetapi terdapat kecenderungan keberpihakan kepada pemerintah atau sebaliknya, berseberangan dengan kepentingan pemerintah. ${ }^{3}$ Dengan demikian MUI senantiasa berhadapan dengan tantangan-tantangan eksistensi diri, penetrasi politik, dan pemenuhan hajat masyarakat luas.

MUI memang mengemban tugas mulia sekaligus berat. Tugas mulia ini menyangkut servis keagamaan yang berkaitan dengan kepentingan umat Islam secara luas di pelbagai aspek kehidupan mereka. Sedang tugas beratnya adalah selalu terbuka kemungkinan pelbagai resiko yang muncul akibat fatwa-fatwa MUI. Pelbagai resiko ini dapat berupa diskriminasi sosial pada kelompokkelompok tertentu, munculnya problem baru, tidak terindahkannya fatwa, tarik menarik kepentingan ekonomi negara,

\footnotetext{
2 Sebagian penelitian yang dilakukan oleh M. Atho Mudzhar menyebutkan bahwa selama kurun waktu 22 tahun (1975 s,d. 1997) MUI telah mengeluarkan sebanyak 76 fatwa. Isi fatwa itu dapat dikelompokkan kedalam lima kategori, yakni ibadah, paham keagamaan, masalah sosial kemasyarakatan, ilmu pengetahuan dan teknologi, serta penerapan status halal makanan dan minuman. Lihat M. Atho Mudzhar Membaca Gelombang ljtihad: Antara tradisi dan Liberasi (Yogyakarta: Titian llahi Press, 1998), 13.

${ }^{3}$ Secara teoretis dapat dikatakan bahwa fatwa-fatwa MUI merupakan hasil dari keadaan sosialbudaya dan sosial-politik tertentu, yang dalam hal ini kedudukan, tugas, dan peran para ulama dalam masyarakat ditetapkan. Lihat M. Atho Mudzhar, Fatwa-Fatwa Majelis Ulama Indonesia Sebuah Studi tentang Pemikiran Hukum Islam Indonesia 1975- 1988 (Jakarta: INIS, 1993), 8.
} 
sampai pada tindakan-tindakan yang berimplikasi hukum positif dalam skala tertentu. Dalam hal inilah MUI sesungguhnya merupakan institusi keagamaan yang mestinya memerlukan pengawalan hukum atau perangkat infrastruktur lainnya pada tataran praksis realisasi fatwa. ${ }^{4}$

Fatwa MUI mengalami perkembangan yang signifikan di bidang-bidang akidah, hukum, dan akhlak. Signifikansi ini tampak semakin tandas pada jumlah fatwa MUI tentang keuangan syariah yang mencapai 116 fatwa. ${ }^{5}$ Sungguh hal ini penting dan menarik untuk dikaji tentang aspek atensi fatwa MUI dan aspek isi fatwa tersebut. Jumlah fatwa tersebut sekaligus memberikan indikasi perhatian besar fatwa MUI terhadap aspek mu'amalah sebagai pilar yang nyata dalam dinamika kehidupan masyarakat. Pada perkembangan saat ini aspek mu'amalah sudah berada dalam sistem perekenomian yang melibatkan pelbagai aspek sebagai konsekuensi dinamika kehidupan. Sebagian aspek-aspek ini adalah kemajuan bentuk-bentuk usaha dan transaksi, keterlibatan teknologi sebagai media transaksi, kemajuan sistem kelembagaan ekonomi termasuk di bidang perbankan, dan tantangan progresif yang dihadapi oleh ekonomi syariah khususnya di Indonesia.

Atas dasar narasi di atas, penulis memandang penting untuk melakukan kajian tentang fatwa MUI yang berkaitan dengan keuangan syariah. Sedang fokus yang penulis tentukan adalah penggunaan kaidah-kaidah fikih (figh legal maxim) dalam fatwa tersebut. Kajian ini penulis lakukan dengan analisis isi (content analysis) dengan tujuan mendeskripsikan isi penggunaan kaidahkaidah fikih dalam fatwa MUI tentang keuangan syariah. Dengan

\footnotetext{
${ }^{4}$ Sebagai perbandingan, di Mesir fatwa Majelis Ulama (Dâr al-Iftâ') dikawal oleh perangkat hukum agar efektif pelaksanaan dan kontrolnya. Fatwa majelis ini sempat terdokumsntasi kedalam buku berjudul Al-Fatâwâ al-Islâmîyah min Dâr al-Iftâ' al-Mișrîyah (Kairo, I 400 H./l970 M.). Buku ini terdiri dari 20 jilid dan memuat fatwa atas 3460 masalah.

${ }^{5}$ Jumlah ini didasarkan atas hasil penelusuran penulis dari pelbagai sumber sampai menemukan fakta otentik berupa naskah fatwa MUI tentang keuangan syariah mulai tahun 2000 sampai dengan 2017. Fatwa pertama bernomor 0 I/DSN-MUI/IV/2000, tanggal I April 2000, tentang Giro, sedang fatwa terakhir bernomor I I6/DSN-MUI/IX/2017, tanggal 19 September 2017, tentang Uang Elektronik Syariah.
} 
analisis isi ini penulis berusaha melakukan kategorisasi fatwa MUI tentang keuangan syariah dan selanjutnya penggunaan kaidahkaidah fikih dalam fatwa tersebut. Kategorisasi fatwa dan penggunaan kaidah-kaidah ini penulis maksudkan untuk menemukan makna yang ada di dalamnya.

Substansi mayor kajian ini adalah metodologi fatwa MUI dan kaidah-kaidah fikih dalam ekonomi Islam. Urgensi kajian tentang dua persoalan mayor ini telah menarik perhatian sejumlah peneliti. Urgensi kajian tentang metodologi fatwa MUI menjadi perhatian penting Al Fakhri Zakirman ${ }^{6}$ dan Khozainul Ulum. ${ }^{7}$ Sedang urgensi kajian tentang kaidah-kaidah fikih dalam ekonomi Islam menarik perhatian penting Syamsul $\mathrm{Hilal}^{8}$ dan Masyhudi Muqorobin. ${ }^{9}$ Empat kajian tersebut memberikaan perhatian terhadap pentingnya fatwa MUI dan urgensi kaidah-kaidah fikih dalam pengembangan ekonomi Islam. Sedang kajian ini secara khusus memberikan kontribusi terhadap isi pemanfaatan kaidah-kaidah fikih dalam fatwa MUI tentang keuangan syariah.

\section{Kedudukan Fatwa Majelis Ulama Indonesia dalam Hukum Islam}

Penulis terlebih dulu mendeskripsikan pengertian fatwa secara etimologs dan termonilogis. Secara etimologis, dalam kitab alMu'jam al-Wâși fatwa diartikan jawaban terhadap sesuatu yang musykil dalam masalah syariat dan perundang-undangan Islam. ${ }^{10}$ Dalam kitab Lisân al-`Arab fatwa secara lughawi dijelaskan dengan terma 'al-futya wa al-futwa', merupakan bentuk isim masdar dari kata ifta', yafti-ifta' yang diartikan memberikan penjelasan atau sesuatu yang difatwakan oleh seorang ahli fikih atau dapat

\footnotetext{
${ }^{6}$ Al Fakhri Zakirman, "Metodologi Fatwa Majelis Ulama Indonesia", Al-Hikmah: Jurnal Dakwah, Vol. I0, No.2 (Desember 20 I6): I 57- I72.

7 Khozainul Ulum, "Fatwa-Fatwa Majelis Ulama Indonesia (MUI) dalam Pemikiran Hukum Islam di Indonesia", Akademika: Jurnal Studi Islam, Vol.8 No.2 (Desember 20। 4): I66-I79.

${ }^{8}$ Syamsul Hilal, "Urgensi Q awa'id al-Fighiyyah dalam Pengembangan Ekonomi Islam", Al-'Adalah: Jurnal Hukum Islam, Vol.X, No. I (Januari 201 I): I- 12.

${ }_{9}$ Masyhudi Muqorobin, "Qawaid Fiqhiyyah sebagai Landasan Perilaku Ekonomi Umat Islam: Suatu Kajian Teoritik", Jurnal Ekonomi dan Studi Pembangunan, Vol.8 No.2 (Oktober 2007): 198-2I 4.

${ }^{10} \mathrm{Ibrahim}$ Anis et.al, Al-Mu'jam al-Wasith, Juz 2 (Kairo: Dar al-Maarif, 1973), 673.
} 
dikatakan 'saya memberikannya sesuatu mengenai permasalahannya apabila saya menjawab permasalahan tersebut'. ${ }^{11}$

Untuk deskripsi secara komprehensif penulis mengeksplorasi pendapat para ahli tentang definisi fatwa. Mereka adalah Qal'aji, ${ }^{12}$ al-Zuhayliy, ${ }^{13} \quad$ al-Juraisi, ${ }^{14}$ Qardawi, ${ }^{15}$ al-Zamakhshari, ${ }^{16}$ dan Schacht. ${ }^{17}$ Dari pendapat mereka penulis dapat menyimpulkan bahwa fatwa adalah penjelasan dari mufti atas pertanyaan tentang hukum shara', baik pertanyaan individual maupun pertanyaan kolektif dalam rangka kepentingan masyarakat, dalam bentuk tulisan maupun lisan yang sifatnya tidak mengikat, melalui proses istinbat atau ijtihad.

Dalam perspektif Islam, fatwa adalah nasehat resmi dari pemegang otoritas tentang pendirian hukum atau dogma Islam. Fatwa tersebut diberikan sebagai respons terhadap masalah tertentu. Sebagian fatwa hanya mengulang-ulang pelbagai pendapat yang telah dikenal, sehingga fungsinya yang terpenting adalah penegasan kembali secara resmi fatwa tersebut. Meskipun demikian, terdapat banyak fatwa sepanjang periode sejarah umat muslim yang bersentuhan secara langsung dengan tuntutan keadaan-keadaan baru, yaitu perubahan sosial dan hukum. ${ }^{18}$

MUI merupakan institusi keagamaan yang memiliki otoritas sebagai pemberi fatwa di Indonesia. Dalam kapasitasnya tersebut MUI diharapkan mampu menerjemahkan dalil-dalil otoritatif yang menjadi landasan penetapan fatwa agar produk hukumnya tepat dan dapat diterima oleh masyarakat muslim di Indonesia. Oleh

\footnotetext{
II Ibn Mundhir, Lisân al-'Arab, Jilid. X (Beirut: Dâr Ihya' al-Turâth al- 'Arabîy, t.th.), I83.

12 Muhammad Rawas Qal'ajî,, Mu'jam Lughah al-Fuqahâ' (Beirut: Dâr al-Nafâis, 1988), 399.

13 Wahbah al-Zuhayliy, Al-Fiqh al-Islâmîy wa Adillatuh, jilid I (Beirut: Dâr al-Fikr, 2004), 35.

${ }^{14}$ Khalid bin 'Abd al-Rahman al-Juraisi, Al-Fatawa (Makkah: Maktabah Malik Fahd, 2008), 39.

15 Yusuf Qardawi, Al-Fatwâ Bayn al-Indibad aw al-Tasayyub (Mesir: Maktabah Wahbah, 1997), 5.

${ }^{16}$ Abū al-Qâsim Mạmmūd ibn_Umar al-Zamakhsyarî, Tafsîr al-Kashshâf, An Haqâ’iq alTanzîl wa Uyūn al-Aqâwîl fí Wujūh al-Tanwîl (Mesir: Muștafa al-Bâbî̀ al-Ḥalabi, t.th.), 367.

${ }^{17}$ Joseph Schacht, An Introduction to Islamic Law (London: Oxford University Press, 1965), 74.

18 M.B. Hooker, Islam Mazhab Indonesia; Fatwa-Fatwa dan Perubahan Sosial, terj, Iding Rosyidin Hasan (Jakarta: Teraju, 2003), 13.
} 
karena itulah dalam produksi fatwa diperlukan metode kerja yang minimal meliputi dua hal, yaitu metode istinbât (pengambilan) hukum dan latar persoalan yang akan difatwakan. Metode istinbât memerlukan kaidah-kaidah fikih dan ushul. Pada praktiknya, MUI lebih banyak melibatkan kaidah-kaidah fikih dalam produksi fatwanya, karena kaidah-kaidah tersebut merupakan perangkat metodis yang berkaitan secara langsung dengan kebutuhan praktis dalam produksi fatwa. Agar keputusan fatwa MUI tepat sesuai dengan persoalan yang difatwakan, maka latar persoalan tersebut juga perlu dikaji secara serius. Untuk keperluan ini MUI sering melibatkan para ahli di bidang persoalan yang bersangkutan, termasuk bidang keuangan syariah.

Kedudukan fatwa MUI dapat dilihat dari perspektif ijtihad hukum Islam. Dalam hal ini Atho Mudzhar memberikaan pendapatnya, bahwa hasil ijtihad ulama dapat dibedakan menjadi empat macam: (1) fikih, (2) keputusan hakim di lingkungan Peradilan Agama, (3) peraturan perundangan di negara-negara muslim, dan (4) fatwa ulama. ${ }^{19}$ Karena fatwa merupakan sebagian dari hasil ijtihad ulama, maka sesungguhnya tidak ada perbedaan substansial di kalangan para ulama tentang ijtihad dan fatwa. Untuk hal ini Abu Zahrah memberikan pandangannya, bahwa perbedaan ijtihad dan fatwa terlihat pada fatwa lebih khusus dibandingkan dengan ijtihad, karena ijtihad merupakan kegiatan istinbat hukum yang selalu dilakukan, baik ketika ada pertanyaan atau tidak ada pertanyaan. Sedang fatwa dilakukan ketika ada kejadian nyata yang memerlukan penjelasan hukum dan ahli fikih berusaha mengetahui hukumnya untuk memberikan penjelasan tersebut. ${ }^{20}$ Dengan demikian, kedudukan fatwa MUI dalam hukum Islam merupakan hasil ijtihad yang bersifat spesifik dan responsif atas persoalan-persoalan hukum Islam yang memerlukan penjelasan hukumnya.

19 Atho Mudzhar, "Fikih dan Reaktualisasi Ajaran Islam", dalam Budi Munawwar Rahman (ed.), Kontekstualisasi Doktrin Islam dalam Sejarah (Jakarta: Paramadina, 1995), 369-370.

20 Muhammad Abū Zahrah, Ușūl al-Fqh (Beirut: Dâr al-Fikrîal- 'Arabî, t.th.), 40 I . 


\section{Deskripsi Singkat tentang Kaidah Fikih}

Pengertian kaidah fikih (qawầid fiqhîyah) dapat dideskripsikan melalui pendapat Tâj al-Dîn al-Subkî dan Muștafâ al-Zarqâ. AlSubkî menjelaskan, bahwa kaidah fikih adalah suatu perkara kulli (universal) yang berlaku pada semua cabang yang banyak yang dengannya diketahui hukum-hukum semua cabang itu. ${ }^{21}$ Al-Zarqa menjelaskan, bahwa kaidah fikih adalah dasar-dasar fikih yang bersifat umum dan bersifat ringkas, berbentuk undang-undang yang berisi hukum-hukum shara' yang umum terhadap pelbagai peristiwa hukum yang termasuk dalam ruang lingkup kaidah tersebut. ${ }^{22}$

Menurut pendapat Must\}afâ al-Zuh\}aylîy dalam kitabnya alQawầid al-Fiqhîyah, bahwa -kaidahkaidah fikih terbagi ke dalam empat klasifikasi sebagai berikut:

1. Al-Qawầid al-Fiqhîyah al-Asâsîyah al-Kubrâ, yaitu kaidah-kaidah fikih yang bersifat dasar dan mencakup pelbagai bab dan permasalahan fikih. Kaidah-kaidah ini disepakati oleh seluruh mazhab. Kklasifikasi pertama ini meliputi kaidah-kaidah:

a. al-umūr bi maqâsisidihâa (segala urusan tergantung niatnya),

b. al-darar yuzâl (tidak boleh membahayakan dan tidak boleh dibahayakan),

c. al-yaqîn la yuzâl bi al-shakk (keyakinan tidak dapat dihapuskan oleh keraguan),

d. al-mashaqqah tajlib al-taysîr (kesulitan mendatangkan kemudahan),

e. al-'âdah muhakkamah (adat kebiasaan dapat dijadikan hukum).

2. Al-Qawầid al-Kullîyah: kaidah-kaidah yang menyeluruh yang diterima oleh mazhab-mazhab, tetapi cabang-cabang dan cakupannya lebih sedikit daripada kaidah sebelumnya. Contoh: kaidah al-kharâj bi al-ḍamân (hak mendapatkan hasil disebabkan oleh keharusan menanggung kerugian) dan kaidah al-darar al-

${ }^{21}$ Asjmuni A. Rahman, Q aidah-Q aidah Figh (Jakarta: Bulan bintang, 1976), II.

${ }^{22}$ Abd. Rahman Dahlan, Ushul Fiqih (Jakarta: Amzah, 20I I), 13. 
ashadd yudfa' bi al-darar al-akhaff (bahaya yang lebih besar dihadapi dengan bahaya yang lebih ringan). Banyak kaidahkaidah ini masuk pada kaidah yang 5, atau masuk di bawah kaidah yg lebih umum.

3. Al-Qawâid al-Madhhabîyah (kaidah mazhab), yaitu kaidahkaidah yang menyeluruh pada sebagian mazhab, tidak pada mazhab yang lainnya. Kaidah ini terbagi ke dalam dua bagian: (a) kaidah yang ditetapkan dan disepakati pada satu mazhab, (b) Kaidah yang diperselisihkan pada satu mazhab. Contoh: kaidah al-rukhaș lâ tunât bi al-Ma âş̦iy (dispensasi tidak diperoleh karena maksiat). Kaidah ini masyhur di kalangan mazhab Shafi'i dan mazhab Hanbali tetapi tidak demikian di kalangan mazhab Hanafi, dan dirinci di kalangan mazhab Maliki.ū

4. Al-Qawầid al-Mukhtalaf fîhâ fì al-Madhhab al-Wâhid: kaidahkaidah yang diperselisihkan dalam satu mazhab. Kaidah-kaidah tersebut diaplikasikan dalam satu furū (cabang) fikih, tidak demikian pada fur $\bar{u}$ yang lainnya, dan diperselisihkan dalam furū ' pada satu mazhab. Contoh: kaidah hal al-`ibrah bi al-ḥ̂l aw bi al-maâl? (apakah hukum yang dianggap itu pada waktu sekarang atau waktu nanti?). Kaidah ini diperselisihkan pada mazhab Shafi'i, oleh karena itu tersebut pada umumnya diawali oleh kata 'hal' (apakah). ${ }^{23}$

Selanjutnya dari pelbagai sumber yang otoritatif penulis dapat memberikan gambaran ringkas tentang kaidah-kaidah Asasîyah dan Kullîyah sebagaimana paparan tabel-tabel dan penjelasan di bawah ini. 
Tabel 1. Ringkasan Kaidah Asasîyah Fikih

\begin{tabular}{|c|c|c|c|c|}
\hline No. & Kaidah Asasîyah (Mayor) & Kode & $\begin{array}{l}\text { Jumlah } \\
\text { Kaidah } \\
\text { Minor }\end{array}$ & $\begin{array}{c}\text { Nomor } \\
\text { Kaidah } \\
\text { Minor }\end{array}$ \\
\hline 1 & 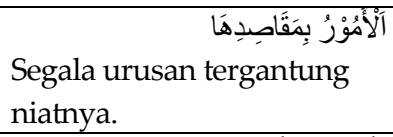 & KM1 & 8 & $2-9$ \\
\hline 2 & 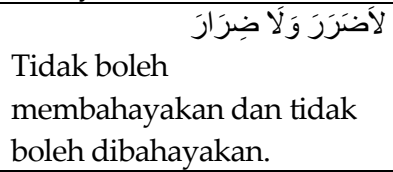 & KM2 & 6 & $11-16$ \\
\hline 3 & 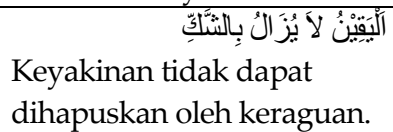 & KM3 & 13 & $18-30$ \\
\hline 4 & 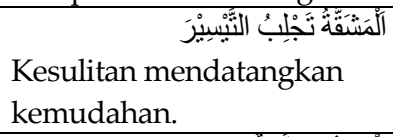 & KM4 & 7 & $32-38$ \\
\hline 5 & 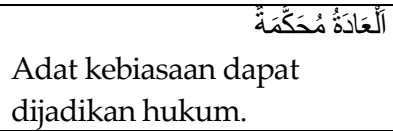 & KM5 & 11 & $40-50$ \\
\hline & Jumlah Kaidah & 5 & 45 & 50 \\
\hline
\end{tabular}

Sumber: Tabel dibuat oleh penulis atas sejumah sumber otoritatif di bidang hukum Islam.

Sejauh referensi yang dilacak oleh penulis terdapat karya yang menyajikan secara rinci kaidah Asasîyah dan kaidah Kullîyah, yaitu karya Muḥammad Mușțafâ al-Zuhaylîy yang berujudul "Al-Qawẩ id alFiqhîyah wa Tat\}bîquhâ fî al-Madhâhib al-Arba'ah". ${ }^{24}$ Selain kaidah asasîyah yang disebutkan di muka, buku ini menyebutkan dan membahas kaidah kullîyah empat mazhab fikih. Hal ini penulis sajikan secara ringkas pada tabel di bawah ini.

${ }^{24}$ Muhammad Musțafâ al-Zuhaylîy, Al-Q awâ`id al-Fiqhîyah wa Tatbîquhâ fi al-Madhâhib alArba`ah (Damsyiq: Dâr al-Fikr, 2006). 
Tabel 2. Ringkasan Kaidah Kullîyah Fikih

\begin{tabular}{|c|c|c|c|}
\hline No. & Kaidah Kullîyah & $\begin{array}{l}\text { Jumlah } \\
\text { Kaidah } \\
\text { Minor }\end{array}$ & $\begin{array}{l}\text { Nomor } \\
\text { Kaidah } \\
\text { Minor }\end{array}$ \\
\hline 1 & $\begin{array}{l}\text { Kaidah Kullîyah yang disepakati } \\
\text { (muttafaqah) }\end{array}$ & 29 & $1-29$ \\
\hline 2 & Kaidah Kullîyah Mazhab Hanafi & 36 & $30-65$ \\
\hline 3 & Kaidah Kullîyah Mazhab Maliki & 47 & $66-112$ \\
\hline 4 & Kaidah Kullîyah Mazhab Syafi'i & 33 & 113-145 \\
\hline 5 & Kaidah Kullîyah Mazhab Hanbali & 35 & $146-180$ \\
\hline 6 & $\begin{array}{l}\text { Kaidah Kullîyah yang } \\
\text { diperselisihkan dalam Mazhab } \\
\text { Maliki }\end{array}$ & 22 & 181-202 \\
\hline 7 & $\begin{array}{l}\text { Kaidah Kullîyah yang } \\
\text { diperselisihkan dalam Mazhab } \\
\text { Syafi'i }\end{array}$ & 21 & 203-223 \\
\hline 8 & $\begin{array}{l}\text { Kaidah Kullîyah yang } \\
\text { diperselisihkan dalam Mazhab } \\
\text { Hanbali }\end{array}$ & 26 & $224-249$ \\
\hline 9 & $\begin{array}{l}\text { Kaidah Kullîyah yang } \\
\text { diperselisihkan dalam Mazhab } \\
\text { Hanbali }\end{array}$ & 27 & $250-276$ \\
\hline & Jumlah & 276 & - \\
\hline
\end{tabular}

Sumber: Tabel dibuat oleh penulis atas karya Muhammad Muștafâ al-Zuhaylîy, 2006.

Tabel di atas menyajikan ringkasan kaidah kullîyah yang disepakati dan kaidah kullîyah pada empat mazhab hukum Islam, yaitu Hanafi, Maliki, Shafi i, dan Hanbali. Jumlah kaidah tersebut sebanyak 276 kaidah yang terbagi atas kaidah kullîyah yang disepakati sebanyak 29 kaidah, kaidah kullîyah pada tiap mazhab sebanyak 151 kaidah, dan kaidah kullîyah yang diperselisihkan pada tiap mazhab sebanyak 96 Kaidah.

Pelacakan lebih jauh tentang kaidah kullîyah dapat dilakukan oleh penulis terhadap sejumlah karya ushul figh empat mazhab hukum Islam. Hasil pelacakan ini menunjukkan bahwa jumlah kaidah kullîyah mencapai ratusan. Jumlah terbanyak kaidah 
terdapat pada Mazhab Shafi'i, yaitu sebanyak 600 kaidah pada kitab Al-Istighnâ' fì al-Furūq wa al-Istithnấ karya Badr al-Dîn al-Bakrîy. Urutan selanjutnya terdapat pada Mazhab Maliki dengan jumlah 548 kaidah pada kitab Anwâr al-Burūq fi Anwâa al-Furūq karya Shihâb al-Dîn al-Qarafîy. Dari semua karya pada empat mazhab hukum Islam dapat diketahui bahwa jumlah kaidah Kullîyah adalah sebanyak 2361 kaidah.

Kaidah-kaidah fikih tersebut dibuat oleh para ahlinya dalam kondisi diperlukan atau belum diperlukan pada saat yang berlangsung ketika kaidah tersebut dibuat. Sejumlah kaidah tersebut disediakan oleh mereka untuk memenuhi kebutuhan penetapan hukum atas sejumlah persoalan yang sedang terjadi atau belum terjadi. Dalam hal ini para ahli memberikan pendapatnya tentang urgensi dan efisiensi kaidah fikih dalam pencarian solusi hukum Islam. Di antara meraka adalah al-Qarafîy, al-Nadwîy, dan al-Zarqâ. Tiga orang ahli ini memberikan pandangannya:

1. Kaidah fikih mempunyai kedudukan istimewa dalam keilmuan Islam karena kecendekiaan ahli fikih terkait erat dengan penguasaan kaidah fikih.

2. Kaidah fikih dapat menjadi landasan berfatwa.

3. Kaidah fikih menjadikan ilmu fikih lebih sistematis sehingga mempermudah seseorang untuk mengidentifikasi produk fikih yang jumlahnya sangat banyak. ${ }^{25}$

4. Kaidah fikih mengikat persoalan fikih yang bermunculan, kaidah fikih lebih memudahkan untuk dihafal dan dipelihara. ${ }^{26}$

5. Urgensi kaidah fikih menggambarkan secara jelas tentang prinsip-prinsip fikih yang bersifat umum, membuka wawasan dan pelbagai jalan pemikiran tentang fikih.

6. Kaidah fikih mengikat pelbagai hukum cabang yang bersifat praktis dengan pelbagai dawâbit, yang menjelaskan bahwa setiap

${ }^{25}$ Shihâb al-Dîn al-Qarafî, Anwâr al-Burūq fi Anwâ` al-Furūq, Juz III (Beirut: Dâr al-Ma'rifat, 1990), 3.

${ }^{26}$ Alū Aḥmad al-Nadwîy, Jamharah al-Qawâiid al-Fiqhîyah fî̀ al-Mu'âmalât al-Mâlîyah, Juz. I (Riyậ: Shirkah al-Râjihî al-Mașrafîyah li al-Istithmâr, 2000), 326. 
hukum cabang tersebut mempunyai satu manât (illat, indikator) dan segi keterkaitan, meskipun objek dan temanya berbedabeda. ${ }^{27}$

\section{Penggunaan Kaidah Fikih dalam Fatwa MUI tentang Keuangan Syariah}

\section{Eksistensi MUI dan Regulasi Kewenangan Fatwanya}

MUI memandang bahwa kemajuan dalam bidang ilmu pengetahuan dan teknologi serta tuntutan pembangunan yang menyentuh seluruh aspek kehidupan, di samping membawa pelbagai kemudahan dan kebahagiaan, juga menimbulkan sejumlah perilaku dan persoalan-persoalan baru. Cukup banyak persoalan yang sebelumnya tidak pernah dikenal bahkan tidak pernah terbayangkan, sekarang hal itu menjadi kenyataan. ${ }^{28}$ Atas kenyataan ini, Helmi Karim memberikan pandangannya, umat Islam meyakini bahwa Islam mampu mengatur kehidupan umat manusia secara sempurna dalam semua aspek kehidupan. Islam sepanjang sejarahnya sejak diturunkan oleh Allah kepada Nabi Muhammad, hal ini tidaklah menjadikan Islam kaku dalam menghadapi tahap-tahap sejarah yang dilaluinya, melainkan sebaliknya, menjadikan Islam semakin dewasa untuk berperan nyata di tengah-tengah kehidupan umat manusia. ${ }^{29} \mathrm{Di}$ antara peran nyata Islam ini adalah eksistensi institusi-institusi Islam, termasuk di dalamnya adalah peran MUI dalam lembaran sejarahnya.

Pada periode sesudah kemerdekaan Indonesia, pemerintah memandang umat Islam sebagai kelompok mayoritas memiliki potensi yang penting. Pemerintah memandang bahwa program pembangunan yang berkaitan dengan agama khsusnya dapat sukses jika didukung oleh para tokoh agama, atau minimal ulama tidak menghalanginya. Hal ini berarti bahwa kerja sama pemerintah

27 Muștafâ Ahmad al-Zarqâ, Al-Madkhal al-Fiqh al-'ÁAmm, Juz II (Damaskus: Maṭba'ah Jâmi'ah, 1983), 943.

${ }^{28}$ Majelis Ulama Indonesia, Himpunan Fatw a MUI Sejak 1975 (Jakarta: Erlangga, 201 I), 3.

${ }^{29}$ Helmi Karim, Konsep Ijtihad Majelis Ulama Indonesia dalam Pengembangan Hukum Islam (Pekanbaru: Fajar Harapan, 1994), I . 
dengan ulama perlu dijalin. Untuk maksud tersebut, pada masa kepemimpinan Soekarno telah didirikan Majelis Ulama yang selanjutnya disusul oleh lahirnya pelbagai Majelis Ulama Daerah tetapi belum mempunyai pegangan dan cara kerja yang seragam. Pada masa selanjutnya, atas prakarsa pemerintah Orde Baru diadakan suatu Musyawarah Nasional Ulama yang terdiri atas utusan wakil-wakil ulama propinsi se-Indonesia di Jakarta pada tanggal 21-28 Juli 1975. Musyawarah ini berhasil secara bulat menyepakati pendirian Majelis Ulama Indonesia (MUI). ${ }^{30}$

Selama waktu 40 tahun sejak kelahiran MUI pada tahun 1975, MUI memberikan perhatian terhadap kesejahteraan rohani umat dan telah menghasilkan fatwa-fatwa yang terkait dengan pelbagai aspek kehidupan masyarakat. MUI telah menerbitkan sejumlah fatwa yang terkait masalah-masalh ibadah, hukum, sosial, olitik, etika, dan ekonomi. Menurut pandangan Helmi Karim, fatwa-fatwa yang dihasilkan oleh MUI kadangkala menimbulkan kontroversi di tengah-tengah masyarakat. Ada pihak yang memandang fatwa MUI sebagai corong penguasa dan ada pula masyarakat yang menilai fatwa MUI tidak konsisten. Munculnya aneka respon seperti itu erat kaitannya dengan kurangnya pengetahuan masyarakat tentang konsep ijtihad MUI dan karakter hukum Islam yang dijadikan referensi oleh MUI dalam produksi fatwa. Oleh karena itu, kajian dalam bidang ijtihad MUI tersebut penting dilakukan. ${ }^{31}$

Karim selanjutnya menjelaskan bahwa sejak MUI berdiri sampai akhir tahun 1990 lembaga tersebut telah membahas masalah-masalah keagamaan dan kemasyarakatan dalam bentuk fatwa yang mencapai 49 buah. Jika dilakukan pengelompokan, fatwa yang dihasilkan oleh MUI sampai tahun 1990 dapat diklasifikasikan kepada bidang ibadat, seperti shalat, puasa, zakat dan haji serta yang berkaitan dengan itu dan bidang non-ibadah

30 lbid, 9.

31 Karim, Konsep ljtihad..., I I. 
seperti masalah al-ahwal al-syakhshiyah (perdata), keluarga berencana, makanan dan minuman, serta bidang-bidang lainnya. ${ }^{32}$

Penelitian lainnya tentang fatwa MUI dilakukan oleh M. Atho Mudzhar dalam bukunya Fatwa-Fatwa Majelis Ulama Indonesia Sebuah Studi tentang Pemikiran Hukum Islam Indonesia 1975-1988.33 Penelitian ini menghasilkan deskripsi tentang sampel fatwa MUI dan metode perumusannya yang penulis sajikan dalam tabel di bawah ini.

Tabel 3. Sampel Fatwa MUI dan Metode Perumusannya

\begin{tabular}{|c|c|c|}
\hline No. & Fatwa-Fatwa MUI & Metode Perumusan \\
\hline 1 & Shalat jum'at bagi para musafir & Talfiq (Ibn Hazm), Qiyas \\
\hline 2 & $\begin{array}{l}\text { Jedah: Miqat bagi jamah haji } \\
\text { dari Indonesia }\end{array}$ & $\begin{array}{l}\text { Talfiq (Ibn Hazm), } \\
\text { Maslahah, Akal }\end{array}$ \\
\hline 3 & $\begin{array}{l}\text { Talak tiga diakui sebagai talak } \\
\text { satu }\end{array}$ & Talfiq \\
\hline 4 & $\begin{array}{l}\text { Larangan perkawinan antar } \\
\text { agama }\end{array}$ & Maslahah al-Mursalah \\
\hline 5 & Pengangkatan anak & Qur'an, Hadis \\
\hline 6 & Penjualan tanah warisan & Akal \\
\hline 7 & Film The massage & Hadis ? (tanpa keterangan) \\
\hline 8 & Film Adam and Eve & Hadis? (tanpa keterangan) \\
\hline 9 & $\begin{array}{l}\text { Pembacaan ayat-ayat al-Qur'an } \\
\text { dalam lagu }\end{array}$ & Akal \\
\hline 10 & $\begin{array}{l}\text { Pemotongan hewan secara } \\
\text { mekanis }\end{array}$ & Akal dan Hadis \\
\hline 11 & $\begin{array}{l}\text { Penghalalan memakan daging } \\
\text { kelinci }\end{array}$ & Hadis \\
\hline 12 & $\begin{array}{l}\text { Pembudidayaan dan memakan } \\
\text { daging kodok }\end{array}$ & Qur'an, Hadis, Akal \\
\hline 13 & $\begin{array}{l}\text { Kehadiran orang Islam pada } \\
\text { perayaan Natal }\end{array}$ & Qur'an, Hadis, Akal \\
\hline 14 & Sumbangan kornea mata & $\begin{array}{l}\text { Akal, Hadis, Fikih, Akal } \\
\text { (Qiyas) }\end{array}$ \\
\hline
\end{tabular}

32 Ibid., I0I

33 M. Atho Mudzhar, Fatwa-Fatwa Majelis Ulama Indonesia, |44- 45. 


\begin{tabular}{|c|l|l|}
\hline 15 & Pencakokan katup jantung & $\begin{array}{l}\text { Qur'an, Hadis, Fikih, Akal } \\
\text { (Qiyas) }\end{array}$ \\
\hline 16 & Keluarga berrencana & Qur'an, Hadis, Akal \\
\hline 17 & $\begin{array}{l}\text { Pengharaman pengguguran } \\
\text { kandungan }\end{array}$ & Qur'an, Hadis \\
\hline 18 & Vasektomi dan tubektomi & Qur'an, Hadis \\
\hline 19 & Izin untuk penggunaan IUD & $\begin{array}{l}\text { Qur'an, Hadis, Akal } \\
\text { (Qiyas) }\end{array}$ \\
\hline 20 & Gerakan Syi'ah di Indonesia & Akal \\
\hline 21 & Gerakan Qadiyani & Akal \\
\hline 22 & Gerakan Inkar al-Sunnah & Qur'an, Hadis \\
\hline
\end{tabular}

Sumber: M. Atho Mudzhar, 1993.

Dalam pelaksanaan tugas fatwa, sebagaimana penjelasan Ma'ruf Amin, MUI memiliki kewenangan dan wilayah fatwa sebagai berikut:

a. MUI berwenang menetapkan fatwa mengenai masalah-masalah keagamaan secara umum, terutama masalah hukum (fikih) dan masalah akidah yang menyangkut kebenaran dan kemurnian keimanan umat Islam Indonesia.

b. MUI berwenang menetapkan fatwa yang berkenaan dengan masalah-masalah keagamaan seperti tersebut pada nomor 1 yang menyangkut umat Islam Indonesia secara nasional atau masalah-masalah keagamaan di suatu daerah yang dapat meluas ke daerah-daerah lainnya.

c. Terdapat masalah yang telah ada Fatwa MUI Pusat, Majelis Ulama Indonesia Daerah hanya berhak melaksanakannya.

d. Jika karena faktor-faktor tertentu fatwa MUI sebagaimana dimaksud nomor 3 tidak dapat dilaksanakan, MUI Daerah boleh menetapkan fatwa yang berbeda setelah berkonsultasi dengan MUI Pusat.

e. Hal yang belum ada fatwanya oleh MUI pusat, MUI Daerah berwenang menetapkan fatwa tentang hal tersebut. 
f. Khusus mengenai masalah-masalah yang sangat musykil dan sensitif sebelum menetapkan fatwa, MUI Daerah diharapakan terlebih dahulu melakukan konsultasi dengan MUI Pusat. ${ }^{34}$

Kewenangan dan wilayah fatwa tersebut telah memberikan gambaran tentang regulasi kewenangan fatwa MUI Pusat dan MUI Daerah. Regulasi ini memberikan peluang kreativitas MUI Daerah untuk memproduk fatwa sesuai dengan kebutuhan pemecahan masalah-masalah hukum Islam di daerahnya. Sebagai referensi untuk pelaksanaan kewenangan MUI Daerah ini perlu diperhatikan hal-hal yang berkenaan dengan dasar, sifat, dan syarat keputusan fatwa, agar terkondisi produksi fatwa MUI Daerah dan MUI Pusat secara selaras dan konsisten.

Amin menjelaskan bahwa dasar umum dan sifat fatwa MUI yang perlu diperhatikan adalah sebagai berikut:

a. Penetapan fatwa didasarkan pada al-Qur'an, Sunnah (hadits), Ijma', dan Qiyas serta dalil-dalil yang mu'tabar.

b. Aktivitas penetapan fatwa dilakukan secara kolektif oleh komisi fatwa.

c. Penetapan fatwa bersifat responsif, proaktif, dan antisipatif. ${ }^{35}$

Sedangkan syarat keputusan fatwa yang harus dipenuhi oleh MUI ketika memproduk fatwanya, sebagaimana penjelasan Amin, adalah sebagai berikut:

a. Setiap keputusan fatwa harus ditanfizkan setelah ditandatangani oleh Dewan pimpinan dalam bentuk Surat Keputusan Fatwa (SKF).

b. Surat keputusan fatwa harus dirumuskan dengan bahasa yang mudah dipahami oleh masyarakat.

c. Dalam surat keputusan fatwa harus dicantumkan alasanalasannya disertai uarian dan analisis secara ringkas, serta sumber pengembilannya.

${ }^{34}$ Ma'ruf Amin, dkk, Himpunan Fatwa Majelis Ulama Indonesia Sejak 1975 (Jakarta: Erlangga, 20II), 7-8.

35 Ibid., 5. 
d. Setiap surat keputusan fatwa yang dikeluarkan harus sedapat mungkin disertai rumusan tindak lanjut dan rekomendasi atau jalan keluar yang diperlukan sebagai konsekuensi dari surat keputusan fatwa tersebut. ${ }^{36}$

\section{Metode Penetapan Fatwa MUI}

Amin menjelaskan bahwa penetapan fatwa MUI dilakukan dengan metode sebagai berikut:

a. Sebelum fatwa ditetapkan hendaknya ditinjau terlebih dahulu pendapat para Imam mazhab dan Ulama yang mu'tabar tentang masalah yang akan difatwakan tersebut secara teliti dalildalilnya.

b. Salah yang telah jelas hukumnya hendaklah disampaikan sebagaimana adanya.

c. Dalam masalah yang terjadi khilafiyah (perbedaan pendapat) di kalangan mazhab, maka:

1) Penetapan fatwa didasarkan pada hasil usaha penemuan titik temu di antara pendapat-pendapat ulama mazhab melalui metode al-jam 'wa al-tawfiq, dan

2) Jika usaha penemuan titik temu tidak berhasil dilakukan, penetapan fatwa didasarkan pada hasil tarjih melalui metode muqaranah dengan menggunakan kaidah-kaidah Ushul Figh Muqaran.

d. Dalam masalah yang tidak ditemukan pendapat hukumnya di kalangan mazhab, penetapan fatwa didasarkan pada hasil ijtihad jama'i (kolektif) melalui metode bayani, ta'lili (qiyasi, istihsani, ilhaqi), istishlahi, dan sadd al-zari'ah. 
e. Penetapan fatwa harus senantiasa memperhatikan kemaslahatan umum (mashalih 'ammah) dan tujuan hukum Islam (maqashid al-syari'ah). ${ }^{37}$

Metode istinbât hukum Islam yang digunakan oleh MUI dalam fatwa-fatwanya menggunakan struktur istinbât yang terdiri atas enam unsur: (1) al-Qur'an, (2) hadis Nabi, (3) ijmâ’, (4) qiyâs, (5) kaidah fikih, dan (6) pendapat para ulama. Secara khusus dalam fatwa tentang keuangan syariah, MUI memperhatikan pendapat peserta rapat pleno Dewan Syariah Nasional sebagai bagian dari klausul penetapan fatwanya.

\section{Kaidah Fikih dalam Fatwa MUI tentang Keuangan Syariah}

Penulis menelusuri sejumlah fatwa MUI tentang keuangan syariah melaui media-media pelacakan inforrmasi media-media berbasis online dan offline. Dari penelusuran ini diperoleh 116 fatwa MUI tentang keuangan syariah. Jumlah fatwa ini terbentang dari fatwa pertama dengan nomor 01/DSN-MUI/IV/2000, tanggal 1 April 2000, tentang 'Giro' sampai fatwa terakhir dengan nomor 116/DSNMUI/IX/20I7, tanggal 19 September 2017, tentang ‘Uang Elektronik Syariah'.

Sejumlah fatwa tersebut penulis deskripsikan dan analisis dengan analisis isi (content analysis). Dengan analisis ini penulis melakukan langkah-langkah sebagai berikut:

a. kategorisasi fatwa MUI sesuai dengan isi fatwa,

b. kategorisasi kaidah fikih berdasarkan rumpun kaidah asasiyah, kaidah kullîyah yang disepakati, kaidah kullîyah mazhab, dan kaidah khusus,

c. kategorisasi kaidah fikih sesuai dengan rumpun kaidah (kode urut dan isi kaidah),

d. pendataan kaidah-kaidah fikih yang digunakan dalam setiap fatwa MUI tentang keuangan syariah (item-item kaidah pada setiap fatwa),

${ }^{37}$ Ibid., 5-6. 
e. pendataan kaidah-kaidah fikih yang digunakan dalam setiap fatwa MUI tentang keuangan syariah sesuai dengan kategori dan rumpun kaidah fikih,

f. analisis statistik untuk memperoleh deskripsi kuantitatif tentang penggunaan kaidah-kaidah fikih dalam fatwa MUI tentang keuangan syariah sesuai dengan kategori dan rumpun kaidah,

g. interpretasi isi sesuai dengan deskripsi statistik penggunaan kaidah-kaidah fikih dalam fatwa MUI tentang keuangan syariah,

h. interpretasi isi lanjutan terhadap hal-hal yang terkait dengan penggunaan kaidah-kaidah fikih dalam fatwa MUI tentang keuangan syariah.

Langkah-langkah analisis isi dalam kajian ini menghasilkan deskripsi statistik dan pemaknaan isinya. Langkah pertama (a) menghasilkan deskripsi statistik ringkasan kategori fatwa MUI tentang keuangan syariah sebagaimana paparan tabel 4. Langkah kedua (b) sampai keenam (f) menghasilkan deskripsi statistik penggunaan kaidah-kaidah fikih dalam fatwa MUI tentang keuangan syariah ${ }^{38}$ sebagaimana paparan tabel 5. Dua tabel ini penulis sajikan secara berturut-turut di bawah ini.

Tabel 4. Ringkasan Kategori Fatwa MUI tentang Keuangan Syariah

\begin{tabular}{|c|c|c|c|c|}
\hline No. & $\begin{array}{c}\text { Kategori } \\
\text { Fatwa }\end{array}$ & Nomor Fatwa & Jumlah & Persen \\
\hline 1 & $\begin{array}{l}\text { Simpanan dan } \\
\text { Investasi }\end{array}$ & $1,2,3,24,97,96$ & 6 & $5,2 \%$ \\
\hline 2 & Surat Berharga & $\begin{array}{l}32,33,41,59,69,70, \\
72,76,94,95,36,63, \\
64\end{array}$ & 13 & $11,2 \%$ \\
\hline 3 & Kongsi & $\begin{array}{l}7,38,115,50,8,55, \\
73,114,4,13,16,23, \\
46,47,48,49,84,90, \\
111\end{array}$ & 19 & $16,4 \%$ \\
\hline
\end{tabular}

${ }^{38}$ Mayoritas kaidah fikih dalam fatwa MUI tentang keuangan syariah bersumber pada Jalâl aI-Dîn Abd al-Rahmân ibnu Abî Bakr al-Suyūtîi, al-Ashbâh wa al-Nazấíir fi Qawâaid wa Furū Fiqh al-Shâfi'îyah (Kairo: Dâr Saa, 2004). 


\begin{tabular}{|c|l|l|c|r|}
\hline No. & \multicolumn{1}{|c|}{$\begin{array}{c}\text { Kategori } \\
\text { Fatwa }\end{array}$} & \multicolumn{1}{|c|}{ Nomor Fatwa } & Jumlah & Persen \\
\hline 4 & Jual Beli & $\begin{array}{l}5,6,22,77,82,71, \\
110,100,75,83\end{array}$ & 10 & $8,6 \%$ \\
\hline 5 & Ekspor-Impor & $34,35,57,60,61$ & 5 & $4,3 \%$ \\
\hline 6 & Hasil Usaha & $\begin{array}{l}9,27,56,101,102, \\
112,62,14,15,18,86\end{array}$ & 11 & $9,5 \%$ \\
\hline 7 & Pasar Modal & $\begin{array}{l}28,37,78,116,42, \\
54,20,40,65,66,80\end{array}$ & 11 & $9,5 \%$ \\
\hline 8 & Pembiayaan & $\begin{array}{l}29,30,44,45,89,91, \\
92,109\end{array}$ & 8 & $6,9 \%$ \\
\hline 9 & Penjaminaan & $\begin{array}{l}11,74,105,43,10, \\
113\end{array}$ & 6 & $5,2 \%$ \\
\hline 10 & Asuransi & $\begin{array}{l}21,39,51,52,53,81, \\
98,106\end{array}$ & 8 & $6,9 \%$ \\
\hline 11 & Gadai & $25,26,68$ & 3 & $2,6 \%$ \\
\hline 12 & Utang-Piutang & $\begin{array}{l}19,17,31,12,58,67, \\
79,103,104\end{array}$ & 9 & $7,8 \%$ \\
\hline 13 & Pensiun & 88,99 & 2 & $1,7 \%$ \\
\hline 14 & Jasa Layanan & $93,85,87,107,108$ & 5 & $4,3 \%$ \\
\hline & Jumlah & & $\mathbf{1 1 6}$ & $\mathbf{1 0 0} \%$ \\
\hline
\end{tabular}

Dari tabel di atas dapat diketahui bahwa jumlah terbanyak fatwa MUI tentang keuangan syariah adalah fatwa tentang kongsi sebanyak 19 fatwa $(16,4 \%)$. Urutan kedua adalah fatwa tentang surat berharga sebanyak 13 fatwa $(11,2 \%)$. Urutan selanjutnya adalah fatwa-fatwa tentang hasil usaha dan pasar modal yang masing-masing mencapai jumlah 11 fatwa (9,5\%). Sedang jumlah tersedikitnya adalah fatwa tentang pensiun sebanyak 2 fatwa $(1,7 \%)$.

Deskripsi tersebut dapat dipahami bahwa fatwa MUI tentang keuangan syariah pada tiga peringkat teratas memberikan perhatian besar terhadap kongsi, surat berharga, serta hasil usaha dan pasar modal. Peringkat ini sekaligus menunjukkan skala prioritas fatwa MUI tentang keuangan syariah dengan prioritas tertinggi pada kongsi dan seterusnya. Sedang prioritas terendahnya 
adalah pensiun, karena pensiun memasuki masa non-produktif dalam keuangan syariah.

Tabel 5. Ringkasan Penggunaan Kaidah Fikih dalam Fatwa MUI tentang Keuangan Syariah

\begin{tabular}{|c|c|c|c|c|c|c|}
\hline No. & $\begin{array}{c}\text { Rumpun } \\
\text { Kaidah } \\
\text { (RK) }\end{array}$ & $\begin{array}{c}\text { Kategori } \\
\text { Kaidah } \\
\text { (KK) }\end{array}$ & $\begin{array}{c}\text { Jumlah } \\
\text { KK }\end{array}$ & $\begin{array}{c}\text { Persen } \\
\text { KK }\end{array}$ & $\begin{array}{c}\text { Jumlah } \\
\text { RK }\end{array}$ & $\begin{array}{c}\text { Persen } \\
\text { RK }\end{array}$ \\
\hline 1 & \multirow{5}{*}{$\begin{array}{l}\text { Kaidah } \\
\text { Asasîyah } \\
\text { (Mayor) }\end{array}$} & $\begin{array}{l}\text { Kaidah } \\
\text { Asasîyah } 1\end{array}$ & 2 & $0,6 \%$ & \multirow[b]{5}{*}{252} & \multirow[b]{5}{*}{$78,0 \%$} \\
\hline 2 & & $\begin{array}{l}\text { Kaidah } \\
\text { Asasîyah } 2\end{array}$ & 63 & $19,6 \%$ & & \\
\hline 3 & & $\begin{array}{l}\text { Kaidah } \\
\text { Asasîyah } 3\end{array}$ & 111 & $34,5 \%$ & & \\
\hline 4 & & $\begin{array}{l}\text { Kaidah } \\
\text { Asasîyah } 4\end{array}$ & 47 & $14,6 \%$ & & \\
\hline 5 & & $\begin{array}{l}\text { Kaidah } \\
\text { Asasîyah } 5\end{array}$ & 29 & $9,0 \%$ & & \\
\hline 6 & \multirow{10}{*}{$\begin{array}{l}\text { Kaidah } \\
\text { Kullîyah } \\
\text { yang } \\
\text { disepakati }\end{array}$} & $\begin{array}{l}\text { Kaidah } \\
\text { Kullîyah } 2\end{array}$ & 2 & $0,6 \%$ & & \\
\hline 7 & & $\begin{array}{l}\text { Kaidah } \\
\text { Kullîyah } 4\end{array}$ & 2 & $0,6 \%$ & & \\
\hline 8 & & $\begin{array}{l}\text { Kaidah } \\
\text { Kullîyah } 5\end{array}$ & 21 & $6,5 \%$ & & \\
\hline 9 & & $\begin{array}{l}\text { Kaidah } \\
\text { Kullîyah } 7\end{array}$ & 2 & $0,6 \%$ & & \\
\hline 10 & & $\begin{array}{l}\text { Kaidah } \\
\text { Kullîyah } 11\end{array}$ & 2 & $0,6 \%$ & & \\
\hline 11 & & $\begin{array}{l}\text { Kaidah } \\
\text { Kullîyah } 15\end{array}$ & 1 & $0,3 \%$ & & \\
\hline 12 & & $\begin{array}{l}\text { Kaidah } \\
\text { Kullîyah } 17\end{array}$ & 1 & $0,3 \%$ & & \\
\hline 13 & & $\begin{array}{l}\text { Kaidah } \\
\text { Kullîyah } 20\end{array}$ & 4 & $1,2 \%$ & & \\
\hline 14 & & $\begin{array}{l}\text { Kaidah } \\
\text { Kullîyah } 21\end{array}$ & 4 & $1,2 \%$ & & \\
\hline 15 & & $\begin{array}{l}\text { Kaidah } \\
\text { Kullîyah } 22\end{array}$ & 1 & $0,3 \%$ & 47 & $15 \%$ \\
\hline
\end{tabular}




\begin{tabular}{|c|c|c|c|c|c|c|}
\hline No. & $\begin{array}{l}\text { Rumpun } \\
\text { Kaidah } \\
\text { (RK) }\end{array}$ & $\begin{array}{c}\text { Kategori } \\
\text { Kaidah } \\
\text { (KK) }\end{array}$ & $\begin{array}{c}\text { Jumlah } \\
\text { KK }\end{array}$ & $\begin{array}{c}\text { Persen } \\
\text { KK }\end{array}$ & $\begin{array}{c}\text { Jumlah } \\
\text { RK }\end{array}$ & $\begin{array}{c}\text { Persen } \\
\text { RK }\end{array}$ \\
\hline 16 & & $\begin{array}{l}\text { Kaidah } \\
\text { Kullîyah } 26\end{array}$ & 7 & $2,2 \%$ & & \\
\hline 17 & \multirow[t]{2}{*}{$\begin{array}{l}\text { Kaidah } \\
\text { Kullîyah } \\
\text { Mazhab }\end{array}$} & $\begin{array}{l}\text { Kaidah } \\
\text { Kullîyah } \\
\text { Mazhab } \\
\text { Hanafi }\end{array}$ & 2 & $0,6 \%$ & & \\
\hline 18 & & $\begin{array}{l}\text { Kaidah } \\
\text { Kullîyah } \\
\text { Mazhab } \\
\text { Hanbali }\end{array}$ & 15 & $4,7 \%$ & 17 & $5 \%$ \\
\hline 19 & $\begin{array}{l}\text { Kaidah } \\
\text { Khusus }\end{array}$ & $\begin{array}{l}\text { Kaidah } \\
\text { Khusus } \\
\text { Hukum } \\
\text { Acara } \\
\text { Peradilan }\end{array}$ & 6 & $1,9 \%$ & 6 & $2 \%$ \\
\hline & Jumlah & - & 322 & $100 \%$ & 322 & $100 \%$ \\
\hline
\end{tabular}

Data pada tabel tersebut didasarkan atas 113 di antara 116 fatwa MUI tentang keuangan syariah yang menggunakan kaidah fikih. Tiga fatwa lainnya tidak menggunakan kaidah fikih, yaitu fatwa nomor 24 tentang safe deposit box, fatwa nomor 28 tentang jual beli mata uang (al-Sharf), dan fatwa nomor 89 tentang pembiayaan ulang (refinancing) syariah. Dalam 116 fatwa MUI tentang keuangan syariah, selain 322 item kaidah pada tabel di atas, terdapat 1 kaidah uşūlîyah yang digunakan dalam fatwa MUI Nomor 77 tentang jual beli emas secara tidak tunai. Kaidah uşūlîyah tersebut adalah:

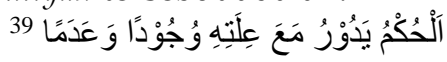

"Hukum berputar (berlaku) bersama ada atau tidak adanya 'illat."

${ }^{39}$ Referensi yang digunakan untuk kaidah ușul fiqh tersebut adalah 'Alî Aḥmad al-Nadwîy, Mawsūah al-Qawâaid wa al-Ḍawâbit al-Fiqhîyah al-Hakịmah li al-Mựmalât al-Mâlîyah fí alFiqh al-Islamîy, Jilid 1(Riyaụ: Dâr 'Alam al-Ma'rifah, 1999), 395. 
Tabel tersebut memberikan gambaran tentang jumlah item kaidah fikih yang digunakan dalam 113 di antara 116 fatwa MUI tentang keuangan syariah, sekaligus makna-makna yang ada di balik jumlah tersebut. Jumlah seluruh item kaidah fikih dalam fatwa tersebut adalah 322 item. Jumlah terbanyak item kaidah fikih menurut rumpun kaidah terdapat pada kaidah asasiyah (mayor) sebanyak 252 item (78\%). Urutan selanjutnya terdapat pada rumpun kaidah kullîyah yang disepakati sebanyak 47 item (15\%), kaidah kullîyah mazhab sebanyak 17 item (5\%), dan terakhir kaidah khusus sebanyak 6 item (2\%). Selanjutnya jumlah terbanyak item kaidah fikih menurut kategori kaidah terdapat pada rumpun kaidah

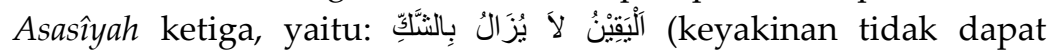
dihapuskan oleh keraguan) sebanyak 111 item. Jumlah ini bersumber dari penggunaan subkaidahnya, yaitu kaidah ke-23:

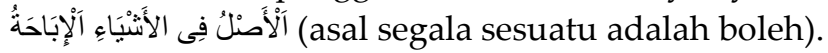

Dalam fatwa MUI, kaidah ke-23 tersebut berbentuk kaidah khusus mu`amalah sebagai berikut:

$$
40
$$

"Pada dasarnya, segala bentuk muamalat itu boleh dilakukan kecuali ada dalil yang mengharamkannya)."

Mayoritas jumlah kaidah ke-23 dalam fatwa MUI tentang keuangan syariah dapat dipahami adanya kecenderungan fatwa tersebut untuk memberikan kesempatan yang leluasa bagi keuangan syariah untuk berkembang dan mencapai kemajuan pesat. Kemajuan ini tentu dalam bingkai ekonomi dengan landasan syariah. Dalam keleluasaan dan kemajuan ini inisiatif dan kreativitas mu amalah memperoleh tempat yang signifikan sejauh belum ditemukan rambu-rambu hukum yang melarangnya (mengharamkannya).

Kecenderungan fatwa MUI tersebut dapat dilacak akarnya dari hadis Nabi SAW tentang mu amalah sebagai berikut:

\footnotetext{
${ }^{40}$ Referensi yang digunakan untuk kaidah ini adalah al-Suyuthi, Al-Ashbâh wa al-Nazấir..., 60.
} 


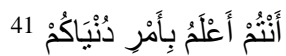

"Kamu lebih mengetahui urusan duniamu."

Hadis Nabi ini dapat dipahami sebagai pemberian kepercayaan kepada umat Islam untuk melakukan usaha mu`amalah secara leluasa. Keleluasaan ini dapat menjadi wadah yang signifikan bagi perkembangan inisiatif dan kreativitas di bidang mu'malah.

Pada bagian lain yang terkait, keleluasaan mu`amalah segera dikendalikan oleh MUI dalam fatwanya. Hal ini dapat dilihat pada jumlah mayoritas item kaidah fikih pada urutan selanjutnya, yaitu pada kaidah Asasîyah ke-2: ضَاضَرَرَرَ وَلَارَ (tidak boleh membahayakan dan tidak boleh dibahayakan) yang mencapai 63 item $(19,6 \%)$. Jumlah ini diperoleh dari jumlah item sub-sub kaidahnya; kaidah ke-12: الضرر يزال (segala bahaya harus

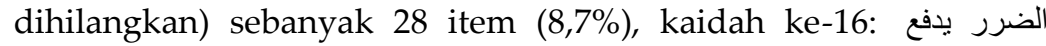
بقدرالإمكان (segala bahaya harus dihindarkan sedapat mungkin) sفع المفاسد مقدم على جلب المصالح: sebanyak 11 item (5,6\%), dan kaidah ke-11 (mencegah kerusakan harus didahulukan daripada mengambil kemaslahatan) sebanyak 17 item (5,3\%).

Peringkat jumlah item kaidah lainnya berada di antara jumlahjumlah item pada kaidah Asasîyah ke-3 dan kaidah Asasîyah ke-2. Rentang dalam peringkat-peringkat ini diisi oleh kaidah Asasîyah ke-4: المشقة تجلب التيسير (kesulitan mendatangkan kemudahan) sebanyak 47 item (14,6\%), kaidah Asasîyah ke-5: العادة محكمة (adat kebiasaan dapat dijadikan hukum) sebanyak 29 item (9,0\%), kaidah Asasîyah ke-1: الأمور بمقاصدها (segala urusan tergantung niatnya) sebanyak 2 item (0,6\%), kaidah Kullîyah ke-5: تصرف الإمام على الرعية منوط (keputusan/kebijakan pemegang otoritas terhadap rakyat harus mempertimbangkan mashlahat masyarakat) sebanyak 21 item $(6,5 \%)$, dan kategori kaidah-kaidah lainnya. Hal ini dapat dipahami secara sistematis bahwa penggunaan kaidah-kaidah fikih

${ }^{4 l}$ Al-Imâm Abū al-Husayn Muslim bin al-Ḥajjâj al-Qushayrîy al-Naysâbūrîy, Șahịhh Muslim (Kairo: Dar al-Kutub, 1918), hadis nomor 2363. 
dalam fatwa MUI tentang keuangan syariah didasarkan pada pertimbangan hukum yang berada dalam rentang tersebut. Fatwa MUI mempertimbangkan rentang keleluasaan mu'amalah agar mencapai kemajuan pesat sejauh usaha mu'amalah tidak membahayakan diri pengusaha dan pihak-pihak lainnya. Tentu saja usaha tersebut semestinya berangkat dari niat baik (good will), dengan adaptasi terhadap tradisi pada jenis usahanya, dan kreatif mencari solusi atas problem-problem usaha. Semua hal yang berkaitan dengan kebijakan mu'amalah melibatkan peran pemerintah atau policy maker yang dituntut untuk menggunakan prinsip kemaslahatan masyarakat dalam kebijakannya.

\section{Penutup}

Majelis Ulama Indonesia (MUI) merupakan institusi keagamaan di Indonesia yang berfungsi memberikan pelayanan di bidang hukum Islam terhadap umat Islam di Indonesia. Pelayanan ini meliputi bidang akidah, ibadah, dan akhlak, termasuk di dalamnya bidang mu'amalah. Sebagian bentuk pelayanan MUI adalah fatwa-fatwa keagamaan dan sebagian fatwa ini menyangkut keuangan syariah. Kedudukan fatwa MUI ini dalam hukum Islam sama dengan hasil ijtihad khusus karena fatwa tersebut diproduk atas kemunculan kejadian atau persoalan yang menuntut penjelasan hukum sebagai landasan perbuatan secara mantap.

Fatwa MUI tentang keuangan syariah berjumlah 116 fatwa; 113 fatwa menggunakan kaidah fikih, tiga fatwa lainnya (fatwa-fatwa nomor 24, 28, dan 89) tidak menggunakan kaidah fikih. Dalam 113 fatwa tersebut MUI menggunakan 322 item kaidah fikih. Jumlah terbanyak item menurut rumpun kaidah terdapat pada kaidah Asasîyah sebanyak 252 item, selanjutnya rumpun kaidah Kullîyah yang disepakati sebanyak 47 item, kaidah Kullîyah mazhab sebanyak 17 item, dan terakhir kaidah khusus sebanyak 6 item. Sedang jumlah terbanyak item menurut kategori kaidah terdapat pada rumpun kaidah Asasîyah ke-3 (keyakinan tidak dapat dihapuskan oleh keraguan) sebanyak 111 item, selanjutnya kaidah 
Asasîyah ke-2 (tidak boleh membahayakan dan tidak boleh dibahayakan) sebanyak 63 item.

Peringkat jumlah item kaidah-kaidah lainnya berada di antara jumlah-jumlah item pada kaidah asasîyah ke-3 dan kaidah asasîyah ke-2. Rentang dalam peringkat-peringkat ini diisi oleh kaidah asasîyah ke-4 (kesulitan mendatangkan kemudahan) sebanyak 47 item, kaidah asasîyah ke-5 (adat kebiasaan dapat dijadikan hukum) sebanyak 29 item, kaidah asasîyah ke-1 (segala urusan tergantung niatnya) sebanyak 2 item, kaidah kullîyah ke-5 (kebijakan pemegang otoritas terhadap rakyat harus mempertimbangkan maslahat masyarakat) sebanyak 21 item, dan kategori kaidah-kaidah lainnya.

Dari perspektif analisis ini, dapat dipahami bahwa penggunaan kaidah-kaidah fikih dalam fatwa MUI tentang keuangan syariah mempertimbangkan rentang keleluasaan mu'amalah agar mencapai kemajuan pesat sejauh usaha mu'amalah tidak membahayakan diri pengusaha dan pihak-pihak lainnya. Rambu-rambu yang terdapat dalam rentang ini adalah usaha semestinya berangkat dari niat baik, dengan adaptasi terhadap tradisi jenis usahanya, dan kreatif mencari solusi atas problem-problem usaha. Hal-hal yang berkaitan dengan kebijakan mu'amalah melibatkan peran policy maker yang dituntut untuk menggunakan prinsip kemaslahatan masyarakat dalam kebijakannya.

\section{Daftar Pustaka}

Amin, Ma'ruf dkk. Himpunan Fatwa Majelis Ulama Indonesia Sejak 1975. Jakarta: Erlangga, 2011.

Anis, Ibrahim et.al, Al-Mu'jam al-Wasith, Juz 2. Kairo: Dar al-Maarif, 1973.

Boy, Pradana, ZTF. "The Functions of Fatwa in Contemporary Muslim Societies: An Indonesian Experience", Salam: Jurnal Studi Masyarakat Islam, Vol.15 No.1, Juni 2012.

Dahlan, Abd. Rahman. Ushul Fiqih. Jakarta: Amzah, 2011. 
Hilal, Syamsul. "Urgensi Qawa'id al-Fiqhiyyah dalam Pengembangan Ekonomi Islam", Al-'Adalah: Jurnal Hukum Islam, Vol.X, No.1, Januari 2011.

Hooker, M.B. Islam Mazhab Indonesia; Fatwa-Fatwa dan Perubahan Sosial, terj, Iding Rosyidin Hasan. Jakarta: Teraju, 2003.

Indonesia, Majelis Ulama. Himpunan Fatwa MUI Sejak 1975. Jakarta: Erlangga, 2011.

Juraysîy (al-), Khâlid bin 'Abd al-Rahmân Al-Fatâwâ. Makkah: Maktabah Malik Fahd, 2008.

Karim, Helmi. Konsep Ijtihad Majelis Ulama Indonesia dalam Pengembangan Hukum Islam. Pekanbaru: Fajar Harapan, 1994.

Mișrîyah, Dâr Iftâ'. Al-Fatâwâ al-Islâmîyah min Dâr al-Iftâ' al-Mişrîyah (Kairo: Mu'assasah Dâr Iftâ' Mișrîyah, 1400 H./1970 M.

Mudzhar, M. Atho. "Fikih dan Reaktualisasi Ajaran Islam", dalam Budi Munawwar Rahman (ed.), Kontekstualisasi Doktrin Islam dalam Sejarah. Jakarta: Paramadina, 1995.

Mudzhar, M. Atho. Fatwa-Fatwa Majelis Ulama Indonesia Sebuah Studi tentang Pemikiran Hukum Islam Indonesia 1975-1988. Jakarta: INIS, 1993.

Mudzhar, M. Atho. Membaca Gelombang Ijtihad: Antara tradisi dan Liberasi. Yogyakarta: Titian Ilahi Press, 1998.

Mundhir, Ibn. Lisân al-'Arab, Jilid. X. Beirut: Dâr Ihya' al-Turâth al'Arabîy, t.th..

Muqorobin, Masyhudi. "Qawaid Fiqhiyyah sebagai Landasan Perilaku Ekonomi Umat Islam: Suatu Kajian Teoritik", Jurnal Ekonomi dan Studi Pembangunan, Vol.8 No.2, Oktober 2007.

Muslim, al-Imâm Abū al-Husayn bin al-Ḥajjâj al-Qushayrîy alNaysâbūrîy, Şahịh Muslim. Kairo: Dar al-Kutub, 1918.

Nadwîy (al-), 'Alî Aḥmad Mawsūă al-Qawâuid wa al-Dawâbit al-Fiqhîyah al-Hakimah li al-Muâmalât al-Mâlîyah fì al-Fiqh al-IsTamîy, Jilid 1. Riyad:: Dâr 'Alam al-Ma'rifah, 1999.

Nadwîy (al-), Alū Ahmad. Jamharah al-Qawâiid al-Fiqhîyah fî̀ alMu'âmalât al-Mâlîyah, Juz. I. Riyâḍ: Shirkah al-Râjihî al-Mașrafîyah li al-Istithmâr, 2000. 
Qal'aji, Muhammad Rawas. Mu'jam Lughah al-Fuqahấ'. Beirut: Dâr al-Nafais, 1988.

Qarafî (al-), Shihâb al-Dîn Anwâr al-Burūq fi Anwâ’ al-Furūq, Juz III. Beirut: Dâr al-Ma'rifat, 1990.

Qarḍawîy, Yūsuf. Al-Fatwâ Bayn al-Indibad aw al-Tasayyub. Mesir: Maktabah Wahbah, 1997.

Rahman, Asjmuni A. Qaidah-Qaidah Figh. Jakarta: Bulan bintang, 1976.

Schacht, Joseph. An Introduction to Islamic Law. London: Oxford University Press, 1965.

Siddiqy (as-), Hasbi. Pengantar Hukum Islam. Jakarta: Bulan Bintang. 1975.

Suyūtî (al-), Jalâl aI-Dîn Abd al-Rahmân ibnu Abî Bakr. al-Ashbâh wa alNazấ'ir fi Qawâiid wa Furū Fiqh al-Shâfi'îyah. Kairo: Dâr Saa, 2004.

Ulum , Khozainul. "Fatwa-Fatwa Majelis Ulama Indonesia (MUI) dalam Pemikiran Hukum Islam di Indonesia", Akademika: Jurnal Studi Islam, Vol.8 No.2, Desember 2014.

Zahrah, Muh\}ammad Abū. Ușūl al-Fqh. Beirut: Dâr al-Fikrî al- 'Arabî, t.th.

Zakirman, Al Fakhri. "Metodologi Fatwa Majelis Ulama Indonesia", Al-Hikmah: Jurnal Dakwah, Vol.10, No.2, Desember 2016.

Zamakhsyarî (al-), Abū al-Qâsim Mah\}mūd ibn 'Umar. Tafsîr alKashshâf, 'An Haqấ'iq al-Tanzîl wa Uyūn al-Aqâwîl fi Wujūh alTanwîl. Mesir: Mușt\}afa al-Bâbî al-H\}alabi, t.th..

Zarqâ (al-), Muștafâ Aḥmad. Al-Madkhal al-Fiqh al-'Āmm, Juz II. Damaskus: Maṭba'ah Jâmi'ah, 1983.

Zuhaylîy (al-),Muhammad Muștafâ. Al-Qawâiid al-Fiqhîyah wa Taṭbîquhâ fi al-Madhâhib al-Arbaah. Damsyiq: Dâr al-Fikr, 2006.

Zuhaylîy (al-), Wahbah. Al-Fiqh al-Islâmîy wa Adillatuh, Jilid I. Beirut:

Dâr al-Fikr, 2004. 